\title{
O controle público da energia elétrica: primórdios no Canadá
}

\author{
Alexandre Ricardi \\ Doutor em História Social, FFLCH/USP \\ Alexandre.ricardi@usp.br
}

Como citar este artigo: Ricardi, Alexandre. "O controle público da energia elétrica: primórdios no Canadá”. Khronos, Revista de História da Ciência, nº 8, pp. 82,103. 2019. Disponível em <http://revistas.usp.br/khronos>. Acesso em $\mathrm{dd} / \mathrm{mm} / \mathrm{aaaa}$.

Resumo: Nesse artigo abordaremos a disputa em torno da produção e distribuição de eletricidade entre governos locais do Canadá e acionistas e diretores de empresas privadas, aos fins do século 19. Questionava-se se o serviço seria implantado e explorado por um monopólio privado ou por instâncias de governo. A gestão municipal foi resultado do movimento Populismo Cívico, que defendia que as companhias de serviços deveriam ser totalmente públicas e, da consequente criação da Hydro-Electric Power Commission em Ontário, para distribuição de energia em 1906 e geração e venda em 1914. Os eventos ocorridos no Canadá alarmaram contra a nacionalização das utilities os investidores e diretores em Toronto e no Brasil da holding Brazilian Traction, retirando do país a tomada de decisões e a administração dos lucros.

Palavras-chave: energia elétrica, distribuição de energia, história da ciência.

\section{Public control of electricity: beginnings in Canada}

\begin{abstract}
In this article we will address the dispute over electricity production and distribution between local governments in Canada and shareholders and directors of private companies in the late 19th century. It was questioned whether the service would be deployed and operated by a private monopoly or by the government. Municipal management was the result of the Civic Populism movement, which argued that utility companies should be fully public and the consequent creation of the Hydro-Electric Power Commission in Ontario for power distribution in 1906 and generation and sale in 1914. The events in Canada alarmed investors and directors in Toronto and Brazil of the Brazilian Traction holding company against the nationalization of utilities, removing decision-making and earnings management from the country.
\end{abstract}

Keywords: electricity, power distribution, history of science. 


\section{Khronos, Revista de História da Ciência \\ № 8, dezembro 2019}

\section{Introdução}

Nesse artigo vamos abordar a disputa acerca da produção e distribuição de energia elétrica entre governos locais de algumas províncias do Canadá e acionistas e diretores de empresas privadas, ocorrida aos fins do século 19, grandemente inflada pela possibilidade de exploração do potencial das cataratas do Niágara e a regulamentação dos serviços públicos. A questão era se o serviço deveria ser implantado e explorado por um monopólio privado ou pelas instâncias de governo praticando tarifas baseadas nos custos de produção, fato que retroalimentou o chamado movimento do Populismo Cívico ou 'people's power'. Com pequenas nuances, diferentes correntes surgiram, prevalecendo a ideia de que as companhias de serviços públicos, as utilities, não poderiam ser objeto de lucro, mas sim deveriam beneficiar os consumidores e a comunidade em geral. ${ }^{1}$

Escolhemos examinar esse cenário em duas partes, o contexto histórico no qual o potencial da região dos Grandes Lagos foi percebido, junto com o momento em que a exploração de força e luz começou a ser implantada na região, e o movimento de regulamentação dos serviços públicos no Canadá: luz, força, gás, telefone e transporte de passageiros. O propósito do gerenciamento municipal desses serviços, com grande envolvimento da opinião pública canadense, foi resultado do movimento citado acima e da criação da Hydro-Electric Power Commission de Ontário, a Hydro, para a distribuição de energia em 1906, autorizada a gerar e vender energia a partir de 1914.

No Brasil, os diretores da holding Brazilian Traction receavam uma possível disseminação desse tipo de proposta, que assustava também investidores, acionistas e diretores em Toronto que temiam a nacionalização das utilities. Os diretores, receosos de que os monopólios recém adquiridos no Rio de Janeiro e em São Paulo estivessem sob ameaça, conceberam a holding, retirando do Brasil a tomada de decisões e a administração dos enormes lucros que proporcionavam. O objetivo deste artigo foi pesquisar e apresentar algumas dessas discussões, seu núcleo mais importante com a criação da Hydro, que geraram a pressão que levou à fusão de companhias no Brasil, com seu controle no Canadá, pois seus investidores desejavam evitar um processo de socialização.

Quanto à regulamentação dos serviços públicos no Brasil a história conta sobre um retraso, com a aprovação de um Código das Águas com modificações pelo Congresso Nacional somente em 1934. Esse código, porém, era a proposta brasileira de regulamentação iniciada por

\footnotetext{
${ }^{1}$ Esse tema está relacionado à nossa tese de doutorado referente à expansão do capitalismo financeiro ao fim do século 19 no Brasil e as interações com o desenvolvimento tecnológico, onde procuramos analisar o caso da construção da usina do Itupararanga, 1911 - 1914, e a criação da Brazilian Traction em 1912, holding sediada em Toronto, Canadá, para gerenciar as mais lucrativas companhias no Brasil, São Paulo Light and Power, Rio de Janeiro Light and Power e São Paulo Electric Co. A Brazilian Traction, por sua vez, era controlada pela Canadian and General Finance Company Limited, assim como a Barcelona Traction e a Mexico Traction, além de outras companhias de serviços públicos em diferentes partes do mundo. Agradecemos ao professor Gildo Magalhães da FFLCH-USP e ao professor Nuno Madureira do ISCTE-Lisboa a revisão e os apontamentos para esse texto
} 
Alfredo Valladão em 1907. Tal análise é relevante, pois a legislação brasileira da Primeira República (1889-1930) foi inspirada, assim como a do Canadá, na experiência dos Estados Unidos na área, sendo que no Brasil a regulamentação dos serviços públicos foi rejeitada por pelo menos trinta anos. Consideramos esse atraso como parte de um projeto político de lideranças brasileiras para beneficiar as empresas estrangeiras que monopolizaram os serviços no país por quase 80 anos. Essa parte da análise, no entanto, deverá ser feita em outro momento.

\section{Território: topografia e cenário histórico}

A região dos Grandes Lagos se estende por cerca de 245 mil km² e sua bacia hidrográfica compreende os lagos Superior, Michigan, Huron, Erie e Ontário e os rios que fluem para eles, com uma única saída para o oceano Atlântico, o rio São Lourenço, que possui uma extensão de 1.197 quilômetros. Às margens desse enorme complexo estão localizadas muitas das maiores cidades do Canadá: Toronto, a cidade mais ao sul, à beira do lago Ontário; Ottawa, capital da província de Ontário, às margens do rio de mesmo nome, que deságua no rio São Lourenço; Montreal na ilha do rio São Lourenço e Quebec às suas margens, quase no estuário no oceano Atlântico.

Os registros históricos da região, que surgiram com o descobrimento das Américas praticamente, trazem que o explorador francês Jacques Cartier em duas viagens, 1534 e 1535-36, tornou-se o primeiro europeu a subir o rio São Lourenço. Cartier publicou em 1545 sua descrição, citando brevemente as cataratas do Niágara. O navegador chegou à grande vila dos nativos Iroquois, chamada de Hochelaga em uma ilha no rio São Lourenço, onde seria fundada em 1642 a Vila Marie de Mont Réal, depois Montreal, de início servindo como um armazém francês para o comércio de peles. Cartier não pode prosseguir, porém, devido às corredeiras do rio, não tendo navegado nos lagos e nem mesmo tendo avistado as cataratas, obtendo notícias delas pelos nativos.

Em 1604, o cartógrafo francês e explorador Samuel de Champlain em seu trabalho Des Sanvages declarou que tais quedas existiam, tendo também recebido notícias delas dos nativos do rio São Lourenço, mas nunca tendo encontrado tais cachoeiras. Champlain informa ainda, pouco depois em 1610, que um jovem francês de nome Etienne Brûlé havia sido deixado com um chefe Algonquino chamado Iroquet, servindo como intérprete entre os franceses e vários grupos de nativos americanos. Viajando com os Algonquinos, Brûlé teria sido o primeiro europeu a vislumbrar as cataratas do Niágara e os Grandes Lagos. ${ }^{2}$

Em 1649 uma nova menção sobre as cataratas aparece quando missionários católicos franceses do Quebec instituíram uma missão entre os Huron, reportando que o lago Erie e as

2 ADAMS, Edward Dean. Niagara Power. History of The Niagara Falls Power Company, 1886-1918. Evolution of its Central Power Station and Alternating Current System. Volume I: History and Power Projects. 1927. Nova York: Bartlett Orr, 1927. P. 5. 


\section{Khronos, Revista de História da Ciência \\ № 8, dezembro 2019}

quedas d'água desaguavam no Lago Ontario sobre uma catarata de assustadora altura. Vinte anos depois, em 1669, outro explorador francês, Robert Cavelier, Senhor de La Salle, navegando pelo rio São Lourenço chegou às cataratas e tornou-se o construtor do primeiro navio comercial, o Griffon, a iniciar a navegação comercial nos lagos.

O franciscano Louis Hennepin, missionário que viajou com La Salle, responsável por alguns relatórios de exploração, fez em 1679 a mais detalhada descrição das quedas, publicada em francês somente em 1697, com uma versão em inglês um ano depois, publicada em Londres. Nessa descrição o Padre Hennepin registrou com surpresa: "Betwixt the Lakes Ontario and Erie, there is a vast and prodigious Cadence of Water which falls down after a surprising and astonishing manner, in so much that the Universe does not afford its Parallel."3 Essa publicação do franciscano foi acompanhada de uma ilustração datada de 1678 na qual é possível ver as quedas no que se viria a ser o território norte-americano e as quedas do lado canadense, claramente divididas pela ilha Goat.

Edward Adams, o presidente da The Cataract Construction Company, que construiu a usina de força original nas cataratas do Niágara, relembra que a designação Niágara aparecia de diferentes formas: a primeira, Ongiara no mapa de Sanson ${ }^{4}$ de 1656, no que parece ser uma confusão porque havia um forte na região cujo nome era Oniagara. Uma segunda designação, Jagara Falls, em mapa de 1692, cuja finalidade era mostrar as nações indígenas da porção oriental da América do Norte. Esse mapa foi reproduzido em 1829 na edição do livro History of the United States or Republic of America de Emma Willard. E ainda, no mapa de 1683, feito pelo já citado franciscano Hennepin, onde uma versão aproximada do nome Niágara aparece, sendo grafado como le grand sauts de Niagara.

Niágara era o nome original dado aos 58 quilômetros do rio que liga o lago Erie ao lago Ontário, com as quedas recebendo outros nomes, como notado em 1892 pelo general Ely Parker, mas o nome do rio eventualmente sobrepôs-se ao das cataratas. Interessante notar que algumas dificuldades podem surgir em relação à designação e pronúncia, e em seu trabalho de 1927, Adams, refere uma curiosa confusão na estação de trem central de Nova York. ${ }^{5}$

Adams também recorda que no rio foi estabelecida a fronteira internacional como determinado pelo Tratado de Gent de 1814, negociado ao fim da guerra de 1812 entre os Estados Unidos e a Grã-Bretanha. A linha internacional que passou a separar os Estados Unidos e o Canadá atravessa pelo rio e também corta os lagos tendo sido demarcada pelos delegados comissários em 1819 e o mapa anexado ao tratado. Assim, o sistema inteiro dos lagos e a drenagem

\footnotetext{
3 ADAMS, Niagara Power, p. 6.

${ }^{4}$ Nicolas Sanson (1600-1667) foi geógrafo na corte de Luís XIII e Luís XIV, considerado o Pai da Cartografia na França. Em seu mapa de 1656, a California foi representada como uma ilha.

${ }^{5}$ Um engenheiro inglês, cujo nome não aparece, ao tentar comprar uma passagem para chegar às cataratas, insistia em usar a pronúncia dos nativos Seneca "Near-gar". Depois de provocar algumas vezes e sempre ouvir a resposta do agente de que não havia tal lugar na rede ferroviária de Nova York, o britânico finalmente replicou: "Eu sei bem. Eu estive lá. Bem, então, me dê um ingresso para Ni-ag'-a-ra, como você o pronuncia incorretamente, senhor!" ADAMS, Niagara Power, p. 14.
} 
pelo rio São Lourenço, como o rio Niágara, tornou-se de importância central para ambos os países, reunindo as principais aglomerações humanas no lado canadense, como citamos acima. No lado estadunidense, grandes cidades surgiram às margens dos lagos, tais como Chicago, Buffalo, Milwaukee, Detroit e Cleveland.

Uma ligação artificial entre o lago Erie e o rio Hudson nos Estados Unidos foi feita por um canal construído em 1825, reunindo a região às mais populosas e industrializadas cidades da costa leste daquele país e cedo também foram realizadas avaliações do volume de água e do potencial das quedas. Adams menciona algumas dessas estimativas: a de 1841, feita pelos engenheiros da Blackwell and Allen; medições oficiais como a de 1868, feita pelo corpo de engenheiros do Exército dos Estados Unidos; de 1901, do Serviço de Pesquisa Geológica dos Estados Unidos; de 1924, o relatório do Smithsonian Institute, Study of Natural Resources, entre outros.

Comparações também foram feitas com outros largos sistemas como as quedas Victoria no rio Zambezi na África Central; Sete Quedas e as cataratas do Iguaçu no rio Paraná, Brasil, e as quedas Kaieteur no rio Potaro, Guiana. Em sua avaliação das vantagens que as cataratas do Niágara tinha sobre todos esses sistemas, Adams se mostrou ansioso ao início, exibindo ao final um pouco de determinismo racial: "But these are all remote away from large centers of civilized life, if not actually in the depths of the jungle, and all located in tropical regions which have never been favorable to occupation by the white race". ${ }^{6}$

As avaliações e análises chegaram a conclusões comuns: a acentuada irregularidade no sistema dos Grandes Lagos da América do Norte, que está a 182 metros acima do nível do mar, seria largamente responsável por seu potencial hidráulico, mais do que o fluxo de águas em direção ao Atlântico, que é de 210 mil pés cúbicos por segundo. ${ }^{7}$ Abaixo, na figura 1, temos a representação da diferença, vendo que entre os lagos Erie e Ontário é a mais pronunciada no sistema, de 326 pés (99,36 metros). Dentro deste intervalo estão: a precipitação direta das quedas com 164 pés (49,99 metros), as corredeiras antes das quedas, 51 pés (15,54 metros) e 5 milhas de corredeiras totalizando 94 pés (28,65 metros) pouco antes de fluir para o lago Ontário. Os restantes 18 pés (5,49 metros) são distribuídos a montante e a jusante do rio Niágara.

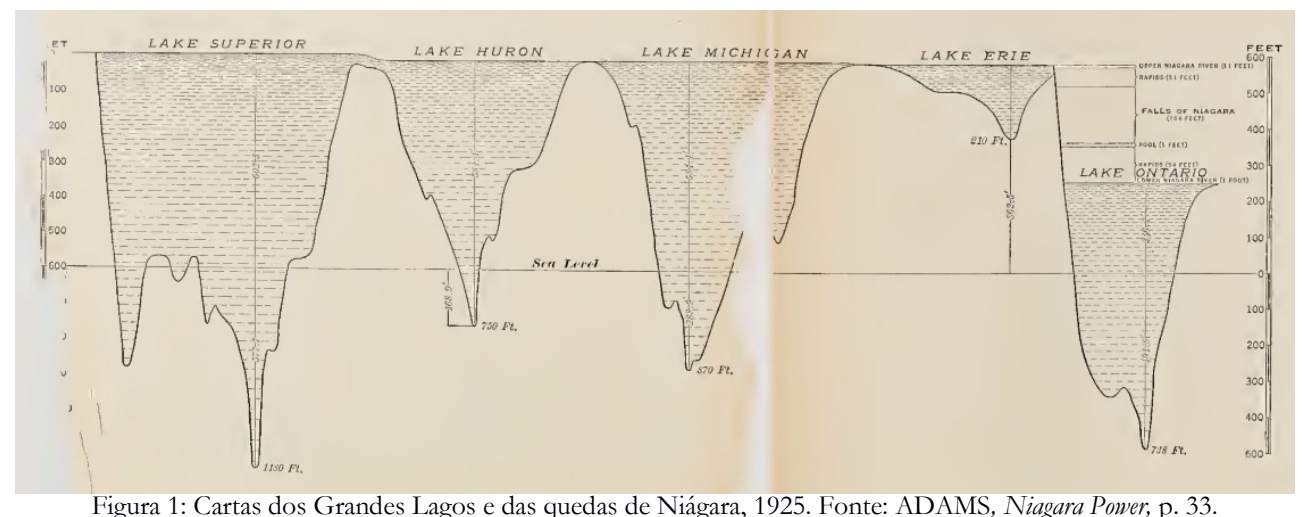

${ }^{6}$ ADAMS, Niagara Power, p. 20.

$75.947 \mathrm{~m}^{3} / \mathrm{s}$ ou 5.946 .538 litros por segundo. 


\section{Khronos, Revista de História da Ciência \\ № 8, dezembro 2019}

Além do cálculo do volume de águas, apresentado em pés cúbicos por segundo, esses levantamentos realizaram cálculos da potência do fluxo em hp por ano, chegando a resultados aproximados: $6.800 .000 \mathrm{hp}$ da Blackwell and Allen em 1841; 6.000.000 hp dos engenheiros do Exército dos Estados Unidos em 1868; 6.000.000 hp do Smithsonian Institute em 1924. Quando contrastes nítidos aparecem nesses cálculos, eles são devidos às diferentes metodologias aplicadas ou referências tomadas, por exemplo, de algumas pesquisas calculando apenas o volume do Lago Erie e do Lago Ontário, a parte "final" do sistema, como a pesquisa do coronel F. C. Shenehon de 1908, que chegou a $4.830 .000 \mathrm{hp}$.

Obviamente, a exploração desse potencial das cataratas do Niágara cedo seria tentada e o primeiro uso conhecido foi feito em 1757-58 pelo francês Chabert Joncaire, soldado, mestre de aduana e legado da França para o comércio na América. Joncaire construiu junto com colonos ingleses um canal a uma curta distância das cataratas para mover uma roda d'água em uma serraria, que, no entanto, parece ter sido usado por John Steadman em 1760. Steadman é mais lembrado por ter ocupado uma larga porção da então chamada ilha Iris, como aparece no mapa de 1819 dos comissários que demarcaram as fronteiras entre os dois países, e por ter povoado a mesma ilha com cabras, que passou então a ser conhecida como ilha Goat.

Em 1805, o juiz Augustus Porter construiu uma serraria e uma loja de ferreiro, se mudando com sua família da cidade de Canandaigua em Nova York em 1806 para as cataratas de Niágara. Porter construiu o primeiro moinho estabelecido no lado americano das cataratas e, em 1809, fundou uma cordoaria e um curtume. As indústrias começaram a se espalhar por toda a região, aproveitando a energia hidráulica para mover suas máquinas, surgindo outras serrarias e moinhos, uma fábrica de papel, uma fábrica de lã e a Trip Hammer Nail Factory. Em 1822, Porter aparece construindo um grande moinho de farinha e em 1823 surgiu outra fábrica de papel, de propriedade de Jesse Symonds.

Em 1825, o juiz Porter e Peter Buell apresentaram uma chamada, Convite aos Capitalistas e Fabricantes do leste para o desenvolvimento nas cataratas do Niágara, nas terras de propriedade deles, no que parece ter sido o primeiro esforço para usar essa força em larga escala para mover fábricas e criar uma cidade. Mesmo assim, o crescimento industrial foi tímido e uma nova tentativa foi feita em 1847 com a circular Para Capitalistas e Fabricantes, oferecendo passagem livre e uso a quem decidisse executar sem demora as obras de um canal hidráulico e suas extensões.

Por iniciativa de Caleb S. Woodhull de Nova York e Walter Bryant de Boston, em 1853 a Niagara Falls Hydraulic Company foi formada e o capital requerido para o início dos trabalhos foi levantado, com as primeiras águas do grande canal sendo lançadas no chamado High Bank em 1857. A partir de então, o número de fábricas se multiplicou e podemos ver na Figura 2 algumas delas já em 1893, todas servidas pelo canal hidráulico no distrito de Lower Milling, no High Bank, despejando suas águas de volta. A Cliff Paper Company usava a força das águas em dois prédios, um no topo do penhasco e outro abaixo, às margem do rio: 


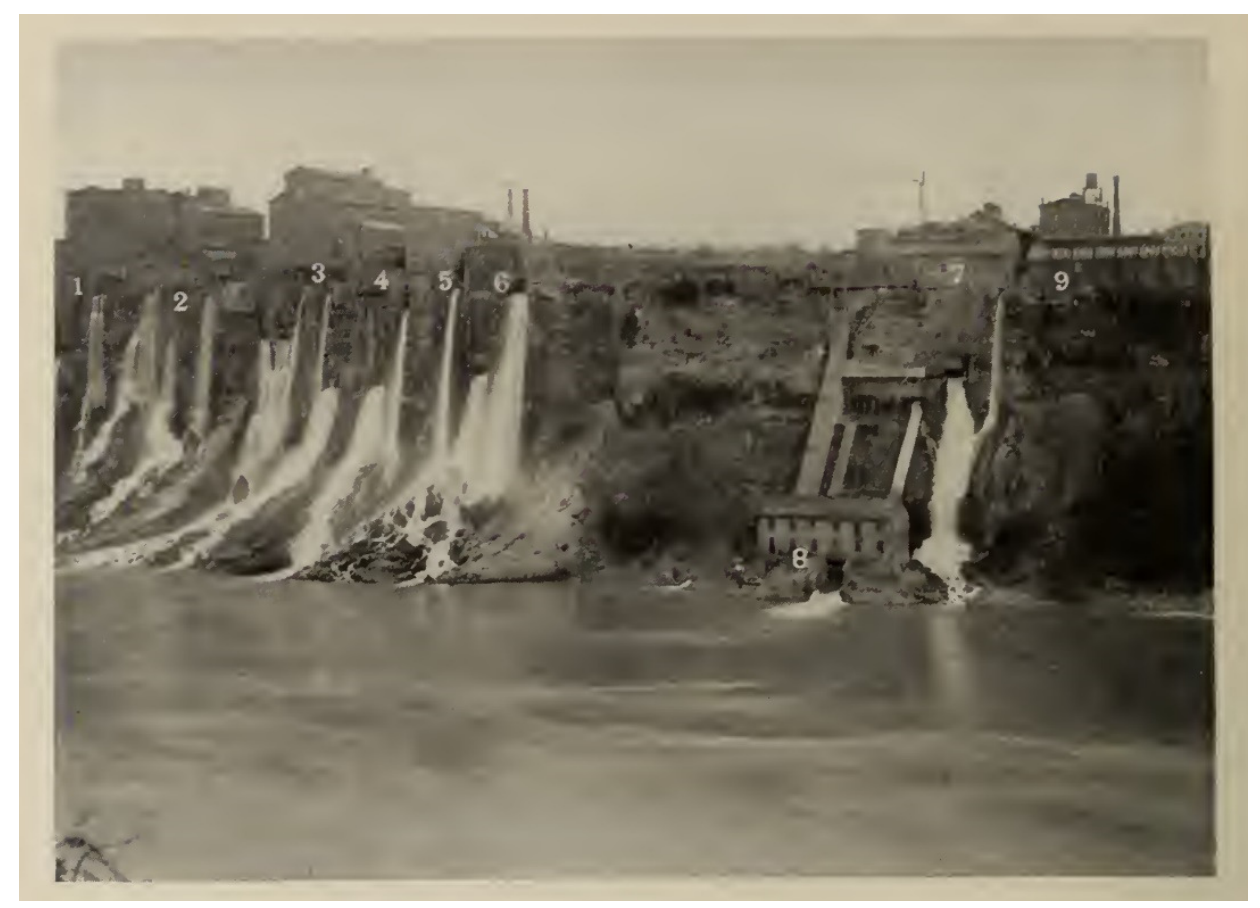

Figura 2: Fábricas servidas pelo canal hidráulico, 1893

1 - Central Milling Company, 2 - Niagara Wood Paper Company, 3 - Schoellkopf \& Mathews Flour Mill, 4 - Pettebone Pulp Mill, 5 - Charles B. Gaskill Flouring Mill, 6 - Niagara Falls City Water Works, 7 e 8 Cliff Paper Company e 9 - Oneida Community Mill. Fonte: ADAMS, Niagara Power, p. 72.

\section{O uso da força}

Quanto à produção de eletricidade, desde pelo menos 1886 vinha sendo considerada. Em um livreto que circulou com o título Forşa das Cataratas do Niágara para Eletricidade, pode ser visto o propósito de iluminar com energia suprida pelas cataratas a cidade de Buffalo, nos Estados Unidos, distante cerca de 32 quilômetros. Naquela época, uma das principais dificuldades era transportar eletricidade a tamanha distância. Devemos lembrar que o modelo de pequenas usinas de energia, um projeto de Thomas Edison na cidade de Nova York, que fornecia eletricidade por corrente contínua somente em áreas adjacentes, a curtas distâncias, já existia desde 1882.

Para as cataratas do Niágara, o primeiro projeto foi de um escritório de Birmingham, Inglaterra, sugerindo o uso de ar comprimido para tal intento, não obtendo sucesso. Em novembro de 1886, os capitalistas dessa iniciativa foram informados por Gardiner C. Sims, da Armington \& Sims Engine Company de Rhode Island, que Thomas Edison andava interessado nesta questão. Sims, que era associado de Menlo Park, o laboratório de Edison em New Jersey, avisava que o inventor e empresário estava estudando as dificuldades da transmissão de eletricidade a longas distâncias especificamente o caso de Niágara e da cidade de Buffalo, incluindo estimativas de custos e ganhos. Em carta, Edison havia feito sua proposta de transmissão começando dos arrabaldes das cataratas por um sistema de corrente direta, a 6 mil Volts com perdas estimadas de $20 \%$ em fios e $6 \%$ em dínamos e "redutores". Essa tensão seria reduzida para 300 a 400 Volts 


\section{Khronos, Revista de História da Ciência \\ № 8, dezembro 2019}

para força e 200 Volts para iluminação para ser distribuída, no que seria conhecida como transmissão Niágara-Buffalo.

No entanto, a corrente alternada já vinha sendo investigada com o objetivo de transportar eletricidade a longas distâncias e, em 1886, Frank J. Sprague, que testava essa corrente desde 1881, recomendou à Edison Electric Illuminating Company de Nova York o seu uso em Niágara. Sprague, entretanto, não acreditava que tal empreendimento seria comercialmente vantajoso, como ele mesmo confessou em carta datada de outubro de 1889: I think it is a problem so uncommercial, in view of the attendant difficulties and risks, that it is better to keep out of. Informou, porém, que tal esforço seria cientificamente possível.

Em fevereiro de 1890, Adams, o já mencionado presidente da The Cataract Construction Company, foi à Europa para conferir os avanços do ramo da eletricidade. Ele queria saber sobre the state of the science of powver development and the art of its transmission, além de procurar por publicações técnicas e conferenciar com engenheiros-construtores. Para isso, visitou rapidamente a Suíça onde fabricantes de turbinas demonstraram interesse pelo desenvolvimento das cataratas do Niágara, e na França deliberou com Marcel Deprez que havia já listado, por carta, seus sucessos com a transmissão a longa distância. ${ }^{9}$

Deprez apresentava uma longa folha corrida de serviços com transmissão de energia elétrica, tendo preparado uma demonstração de transmissão local na Exibição Universal de Paris de 1881; em Munique, em 1882, uma transmissão à distância de 57 quilômetros em fios de ferro de 4 1 1 2 milímetros e em 1883, para a Northern Railway of France, a uma distância de 8 quilômetros. Deprez também havia construído em 1884 uma linha experimental entre Vizille e Grenoble, uma distância de 14 quilômetros em fios de cobre de 2 milímetros de diâmetro; em 1886, uma de corrente direta entre Creil e Paris, uma distância de 56 quilômetros, em fios de cobre de 5 milímetros de diâmetro, experiência financiada pela família Rothschild; e, em 1889, uma linha de transmissão de 15 quilômetros entre as cataratas Les Jarrauds (produção de $61 \mathrm{~kW}$ ) e a cidade de Bourganeuf, com fios de 5 milímetros de diâmetro. Todos esses experimentos, avisou Deprez, foram acompanhados pela Comissão Oficial e publicados em jornais científicos, como o da Academy of Sciences e a Lumière Eléctrique.

Embora Deprez tenha se destacado como um pioneiro da transmissão de luz e força, um grande embaraço era o fato de os valores de magnitude de energia que seriam produzidos nas cataratas do Niágara serem muito maiores do que os testados até aquele momento a longas distâncias. A limitação das máquinas geradoras também constituía um obstáculo e Adams enumerou as mais potentes máquinas elétricas e hidráulicas produzidas em 1890, como demonstrado a seguir:

8 ADAMS, Niagara Power, p. 150-2.

9 Adams visitou, entre outras: Zurique, Maschinenfabrik and Escher, Wyss \& Company, Genebra, Faesch and Picard, Lucena, Theodor Bell \& Cie, Winterthur, Jacob Reiter \& Company. ADAMS, Niagara Power, p. 165. 
Quadro 1: Maiores máquinas hidráulica e elétricas em uso.

\begin{tabular}{|c|c|c|c|}
\hline Fabricante & HPs & $\mathbf{k W}$ & Tipo de corrente \\
\hline Siemens and Halske, Berlim & 1.000 & 746 & Corrente direta \\
\hline Oerlikon Works, Suíça & 600 & 447 & Corrente direta \\
\hline $\begin{array}{c}\text { Gan₹ \& Company, Budapeste } \\
\text { Escher, Wyss \& Company, Zuri- } \\
\text { que }\end{array}$ & $\begin{array}{c}14 \text { turbinas de } 1000 \\
\text { cada }\end{array}$ & 7.460 & Alternador monofásico \\
\hline
\end{tabular}

Fonte: ADAMS, Niagara Power, p. 171.

Outras ocorrências também foram observadas nessa viagem à Europa e dois bem-sucedidos casos protagonizados pela suíça Oerlikon Works foram listados: o primeiro foi a transmissão de força elétrica de 12 geradores de $70 \mathrm{hp} \mathrm{cada} \mathrm{(total} \mathrm{de} 624 \mathrm{~kW}$ ) em corrente direta para a Trans-Andine Railway perfurar túneis no Chile em 1891. O segundo, o marco que consolidou a corrente alternada para o transporte de eletricidade a longas distâncias em 1891, a transmissão bem-sucedida na Exposição Universal na Alemanha de 300 hp (224 kW) a uma distância de 174 km, entre Lauffen e Frankfurt, um projeto do engenheiro C. E. L. Brown da Oerlikon Works. Parecia que as dificuldades para o transporte de grandes quantidades de eletricidade estariam superadas, tornando as perspectivas de produção ilimitadas, possibilitando a construção de usinas maiores, como as projetadas em Niágara, the greatest hydro-electric enterprise in the world, with water turbines larger than any at that time in existence. ${ }^{10}$

Se dermos um salto no tempo, observando números de 1925, veremos que os prognósticos já haviam deixado o político Adam Beck (1857-1925) alarmado anos antes, pois do total prodigioso para a época de energia produzida pela Canadian Niagara Power Company, Limited, cerca de 50 mil hp $(37.285 \mathrm{~kW})$ eram enviados para o Estado de Nova York e cerca de $30 \mathrm{mil} \mathrm{hp}$ $(22.371 \mathrm{~kW})$ eram enviados para as indústrias na Província de Ontário. Somente $20 \mathrm{mil} \mathrm{hp}$ (14.914 kW) eram enviados e distribuídos pela Hydro-Electric Power Commission de Ontário, que o revenderia com preços subsidiados aos consumidores canadenses dessa província. ${ }^{11}$ A Canadian Niagara Power Company era controlada por uma corporação norte-americana e poderia explorar até 100 mil hp $(74.570 \mathrm{~kW})$ do total de 475 mil hp $(354.207 \mathrm{~kW})$.

Todo esse potencial era explorado pela empresa privada, exatamente quando as discussões se inflamaram no início do século, como Beck indica. Tais debates levaram muitos consumidores no Canadá a acreditarem que a propriedade pública, ou pelo menos a competição pública, em um regime de não monopólio, seria preferível ao controle por um empreendimento

10 ADAMS, Niagara Power, VII

11 ADAMS, Niagara Power, p. 229. 
privado. As tarifas de baixo custo propostas eram bastante atraentes para os consumidores sensíveis a apelos por preços mais baratos e serviços de melhor qualidade, reivindicações recorrentes que apareciam nos jornais.

\section{O Populismo Cívico}

O movimento surgido ao final do século 19 na Província de Ontário, Canadá era liderado por políticos que atuavam na esfera municipal. Eles procuraram mobilizar a opinião pública contra a geração e distribuição de hidroeletricidade como monopólio privado, questionando sobre a configuração dos serviços públicos em geral: gás, telefone, transporte de passageiros e eletricidade. Esses políticos eram os primeiros que sentiam the anger of consumers about poor service and high rates rather than members of the federal and provincial parliament. ${ }^{12}$

Entre as muitas reivindicações estavam a propriedade pública das companhias de serviços, as utilities, e o fornecimento de luz e força aos municípios com base no preço de custo. Algumas dessas propostas se espalharam pelo Canadá, com variações, mas seus motivos tinham pontos em comum, sendo um dos principais a acusação de que os capitalistas buscavam altos lucros e se recusavam a estender seus serviços aos subúrbios das cidades. As motivações derivaram da maneira como os serviços públicos foram estabelecidos no país, concessões municipais dadas a grupos privados, que monopolizavam serviços urbanos como transporte de passageiros, eletricidade, telefonia e gás, mas com a esfera municipal submetida aos demais níveis do governo.

O movimento foi classificado pelos autores Armstrong e Nelles como a protest against inadequate service of Public Utilities, made by arbitrary and predatory monopolies, by a small elite grew greedily rich. Segundo esses autores, essa situação tornou a experiência comum a várias cidades do país, com a consequência de convencer alguns consumidores de que o monopólio privado deveria ser rejeitado.

\section{Causas}

Inicialmente, nós devemos considerar como estavam estabelecidas no Canadá as relações entre os poderes governamentais e os serviços públicos para compreender esse movimento e suas consequências, lembrando que não emergiu como movimento bem articulado e com a importância que ganhou ao longo do tempo. A ordem burocrática no então domínio do Canadá estava dividida em três esferas, com poderes sobrepostos e predominância do nível federal sobre

12 ARMSTRONG, Christopher e NELLES, H. V. Monopoly's Moment. The Organization and Regulation of Canadian Utilities, 1830-1930. 1986, Philadelphia: Temple University, 1986. P. 141. 
os demais. Assim, o Domínio, o nível federal, era liderado pelo Primeiro Ministro, sob supervisão do Parlamento; no nível provincial, as comissões de serviços públicos atuavam e, pelo menos no nível municipal, um conselho de administração era eleito. Consequentemente, a legislação provincial prevalecia sobre as leis municipais, dando origem a situações muito características, com os políticos que estavam mais próximos da população, os consumidores dos serviços públicos, estando mais distantes da capacidade final de tomada de decisão. ${ }^{13}$

Por volta da década de 1890, escândalos de suborno e corrupção envolvendo funcionários públicos e empresas privadas estavam sendo amplamente divulgados na imprensa. O problema era considerado de grande gravidade, pois autoridades e políticos da esfera federal apareciam envolvidos nesses escândalos recorrentemente, deixando algumas lideranças ofendidas pelo tratamento dado às suas cidades. Além disso, o apelo à esfera federal tornou-se um subterfúgio para as companhias privadas escaparem do ímpeto da regulamentação quando este começou nos municípios.

Em seguida, o rearranjo desejado foi treinar os funcionários municipais para a administração dos serviços públicos, diminuindo as possibilidades de reparar ofensas e estimular o crescimento do patrimônio público. As queixas contra os capitalistas que detinham os monopólios afirmavam que eles eram protected by sympathetic judges and their own guile, entrepreneurs were able to devote most of their energies to subduing competition, to making sure that "natural" monopolies stayed that way. ${ }^{14}$

Além disso, havia queixas de que as companhias privadas de serviços públicos recusavam ou procrastinavam pedidos de extensão de linhas de eletricidade e de bondes a tração elétrica, para os subúrbios das cidades. As empresas, diziam seus críticos, pareciam interessadas em explorar apenas as regiões mais lucrativas das cidades, onde o movimento de lojas, indústrias e escritórios estava concentrado e eram mais densamente povoadas. Devemos lembrar aqui que, no início do século 20, a maioria das cidades ainda não havia avançado sobre seus subúrbios, quando indústrias e residências começaram a ser instaladas em locais distantes dos centros.

Os líderes do movimento recorriam constantemente em seus discursos às queixas dos consumidores contra as tarifas consideradas muito altas, praticadas pelas companhias. A insistência das empresas em solicitar autorizações de reajustes nas tarifas aos Conselhos Municipais também foi motivo de algumas queixas, reforçando a tese de que os monopolizadores estavam mais interessados em lucros do que em oferecer serviços de qualidade.

Para ilustrar como o monopólio do preço era prejudicial aos consumidores, Adam Beck, um dos líderes do Populismo Cívico, em seu discurso à legislatura de 1905, atacou a fusão das sete empresas que resultou no monopólio de luz e força da Montreal Light, Heat \& Power

${ }^{13}$ Depois que uma revolta nacionalista foi reprimida pela Inglaterra, o Alto e o Baixo Canadá (Quebec e Ontário) foram unidos pela Lei da União de 1840. A coroa britânica concedeu o direito de eleger seus representantes para uma Assembleia, mas manteve a nomeação do governador. Com a Lei Britânica da América do Norte de 20 de março de 1867, as colônias britânicas do Alto e Baixo Canadá e os territórios de New Brunswick e Nova Escócia tornaram-se Domínio da Coroa ou Confederação do Canadá

14 ARMSTRONG e NELLES, Monopoly's Moment, p. 141. 
Company em 1901 em Montreal. ${ }^{15}$ Controlada por Herbert Samuel Holt até 1944, esta companhia obteve um grande aumento de tarifas, como Beck acusava: lighting rates were raised from 40 per cent, to 80 per cent, and power rates were also raised to prices of from $\$ 30,00$ to $\$ 70,00$ per hpper annum..$^{16}$ Emerson Biggar informa que para o ano de 1914, as tarifas de força praticadas por essa companhia privada de Montreal variaram de $\$ 30,00$ a $\$ 100,00$ o hp per annum, e as tarifas de iluminação residencial variaram de 6 a 7 1/2 cents.

Para efeitos de comparação, na cidade de Toronto, a Toronto Electric Light Co. cobrava 8 cents pelo kW-hora para residências, 8 a 12 cents a iluminação comercial e de 2 a 6 cents pela força. Biggar menciona que as tarifas da Hydro System no mesmo ano haviam sido reduzidas a praticamente metade dos valores cobrados pelas concessionárias privadas: to such a point that the average revenue obtained was 4 c for residence, 2.85 c for commercial, lighting and $1.31 \mathrm{c}$ to power users. ${ }^{17}$

De acordo com Armstrong e Nelles, parte dos consumidores canadenses chegou à conclusão de que possuir e controlar a própria companhia de serviços públicos era a única e melhor maneira de reparar os estragos e os maus serviços oferecidos pelas grandes corporações privadas, mas isso só seria possível após marcadas mudanças políticas. O apoio popular cresceu lentamente mais principalmente após 1900, com os políticos da esfera municipal assumindo papel cada vez mais relevante, se colocando à frente do movimento. ${ }^{18}$

Entre os resultados, a criação da Hydro-Electric Power Commission em 1906 na província de Ontário, inicialmente apenas para distribuir eletricidade. Em 1914, a Hydro, como ficou mais conhecida, obteve autorização para geração de eletricidade, entrando em concorrência direta com os fornecedores privados. A partir daí, a forma mais comum de regulamentação no Canadá foi a comissão provincial e Comissões de Serviços Públicos apareceram na Nova Escócia e Quebec em 1906; New Brunswick, em 1910; Manitoba, em 1912 e em Alberta, em 1915.

Outro motivo relevante, que contribuiu para aquecer esse debate, foi o enorme potencial de 475 mil hp $(354.207 \mathrm{~kW})$ previstos para as cataratas do Niágara. O lado americano vinha recebendo melhorias desde 1895-6, com a inauguração de uma usina hidrelétrica para fornecer energia à cidade de Buffalo. ${ }^{19}$ No lado canadense, três empresas privadas obtiveram concessões, com o potencial que poderiam explorar como vemos a seguir:

${ }^{15}$ As seguintes companhias foram incorporadas: The Montreal Gas Company; The Royal Electric Company; The Montreal and St. Lawrence Power Company; The Imperial Light Company; The Lachine Rapids Hydraulic and Land Company; The Citizens Light and Power Company e The Standard Light and Power Company.

16 BECK, Adam. The Public interest in the Niagara Falls Power Supply. Speech by the Honorable Adam Beck, MPP in the Legislature. 1905. Toronto: L.K. Cameron, May, 1905. P. 7.

${ }_{17}$ BIGGAR, Emerson Bristol. Hydro-Electric Development in Ontario. A History of Water-Power Administration under the Hydro-Electric Power Commission of Ontario. 1920, Toronto: The Ryerson Press, 1920. P. 95.

18 ARMSTRONG e NELLES, Monopoly's Moment, p. 149.

${ }^{19}$ EDF Foundation, 150th Anniversary of Nikola Tesla's Birth. Tesla's Wonderful World of Electricity. 2007. EDF

Foundation / Reprograf: Belgrado, 2007. P. 14. 


\begin{tabular}{|c|c|c|}
\hline \multicolumn{3}{|c|}{ Quadro 2: Companhias canadenses - Potencial das cataratas do Niágara } \\
\hline The Canadian Power Company & $\begin{array}{c}\text { controlada por uma corporação } \\
\text { norte-americana }\end{array}$ & $100 \mathrm{mil} \mathrm{hp}(74.570 \mathrm{~kW})$ \\
\hline The Ontario Power Company & $\begin{array}{c}\text { investimentos norte-americanos } \\
\text { The Electrical Development } \\
\text { Company }\end{array}$ & $\begin{array}{c}\text { controle do Sindicato William } \\
\text { Mackenzie }\end{array}$ \\
\hline & Total & $125 \mathrm{mil} \mathrm{hp}(93,212 \mathrm{~kW})$ \\
\hline & $475 \mathrm{mil} \mathrm{hp}(354,207 \mathrm{~kW})$ \\
\hline
\end{tabular}

Fonte: BECK, The Public interest, p. 3.

Apenas para comparar, apresentamos o potencial das maiores usinas hidrelétricas no Brasil em períodos aproximados: em São Paulo, usina de Parnaíba, construída pela São Paulo Light and Power em 1901, alcançando 16 mil kW em 1911; usina de Itupararanga, construída pela São Paulo Electric Co. em 1914, com 30 mil kW, alcançando 56 mil kW em 1925; usina de Cubatão, construída pela São Paulo Light and Power em 1926, alcançando 76 mil kW em 1928; e usina de Fontes no Rio de Janeiro, construída pela Rio de Janeiro Light and Power em 1908 com 24 mil kW. Dadas as proporções demográficas e o consumo industrial entre as regiões atendidas por essas plantas no Brasil e as regiões que seriam atendidas pela produção de Niágara, esses números servem para ilustrar a exata importância desse potencial no início do século 20.

Em seu discurso de 1905, já citado, Beck fez uma comparação do custo por hp entre o vapor e a força elétrica, para avaliar as vantagens da exploração de tamanho potencial elétrico. Beck queria convencer o governo da província de Ontário a implementar o desenvolvimento, procurando demonstrar que, do total de $475 \mathrm{mil} \mathrm{hp}$, apenas $120 \mathrm{mil} \mathrm{hp}(89.484 \mathrm{~kW})$ estavam sendo explorados. No entanto, o político canadense estava ciente e advertiu que grande parte desse potencial não seria entregue à província de Ontário, mas que seria vendido por companhias nos Estados Unidos. Beck dizia que ambas as companhias, The Ontario Power Company e a Canadian Niagara Power Company já estavam fazendo isso. ${ }^{20}$

Argumenta ainda que os consumidores canadenses absorveriam rapidamente os 120 mil hp, se tivessem a oportunidade de recebê-las das empresas concessionárias, o que resultaria em tarifas mais baratas. Devemos relembrar que Buffalo no Estado de Nova York, foi a primeira grande cidade americana, 255 mil habitantes em 1890, a ser suprida com eletricidade gerada de Niágara em 1896, mas outras cidades estavam próximas e poderiam ser interconectadas à rede. No lado canadense, Toronto, Hamilton, Windsor e Sandwich, em frente de Detroit; no lado

\footnotetext{
${ }^{20}$ Biggar explica: At this time the Canadian Niagara Power Co. was only generating about 17,000 h.p., of which 15,000 h.p. was sold to the Niagara Falls Power Co. on the New York side. The Ontario Power Co. was not yet ready to deliver the first units of the 30,000 h.p. which it had contracted for in New York state. The Electrical Development Co. were installing its first 50,000 h.p. for Toronto, but this would not be ready till 1907. BIGGAR, Hydro-Electric Development, p. 56.
} 
americano, Rochester, Oswego e Syracuse. Na década de 1920, cerca de 250 municípios de ambos os países, eram servidos com luz e força geradas nas cataratas do Niágara, como podemos ver abaixo ${ }^{21}$ :

Figura 3: Mapa da rede de distribuição de energia a partir das cataratas do Niágara.

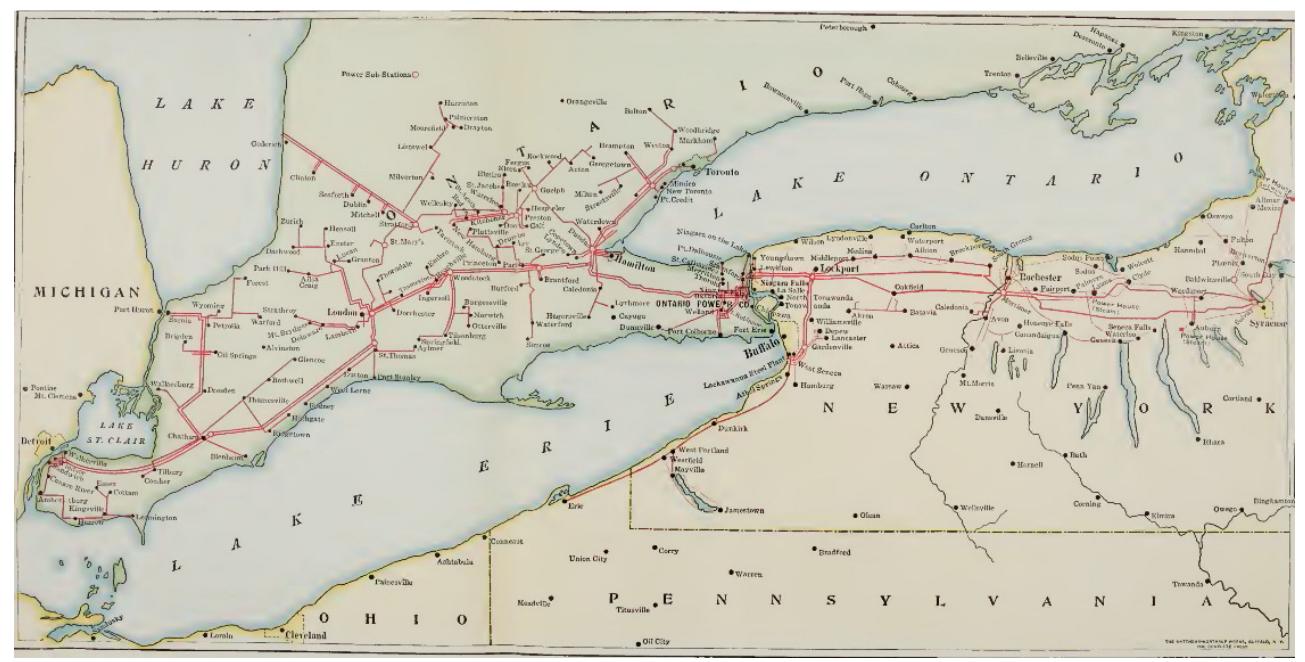

Fonte: Hydro-Electric Power Commission, Hydro-Electric Power, 1920.

\section{Os expoentes: algumas propostas}

Alguns membros do Populismo Cívico postulavam que a regulamentação, mais que o monopólio, era um produto social e político e uma maior difusão desse entendimento resultou em propostas de controle local, em nível municipal ou provincial, e de propriedade pública, da comunidade, como Armstrong e Nelles trazem. Entre as primeiras e principais figuras do surgimento e desempenho desse movimento estava William D. Lighthall (1857-1954), um dos precursores do movimento chamado 'poder do povo' em Ontário, ... an anti-corporate, anti-monopoly critique of the private power industry. O canadense McDowall usa a expressão 'the crusade for 'people's power'. ${ }^{22}$

Nos Estados Unidos, trabalhos publicados, como o de Edward W. Bemis em 1899, Municipal Monopolies. A Collection of Papers by American Economists and Specialists, pode ser tomado como exemplo de como o tema da atuação municipal nos serviços públicos estava suscitando debates, mas neste país essa discussão tinha uma abordagem mais acadêmica principalmente. Neste trabalho, especialistas refletem sobre temas como: serviço de águas e esgotos, iluminação

${ }^{21}$ Hydro-Electric Power Commission of Ontario, Hydro-Electric Power in the Niagara District. Province of Ontario, Canada. 1920, Hydro-Electric Power Commission of Ontario, 1920. P. 9.

22 MCDOWALL, Duncan, The Light: Brazilian Traction, Light and Power Company Limited, 1899-1945. 1988. Toronto: University of Toronto Press, 1988. P. 178. 
elétrica municipal, tração elétrica no transporte de passageiros; gás e regulação ou propriedade privada, concessões municipais, entre outros. ${ }^{23}$

No Canadá, a experiência direta, ao invés de estudos ou análises acadêmicas, foi preponderante, pois os recursos eram diferentes, e também porque os líderes do movimento canadense eram quase todos oficiais eleitos. De acordo com Armstrong e Nelles, Lighthall era a exceção, tendo participado dos dois círculos. Uma de suas características mais importantes era que he might be classified as one of the type of academics or professionals who took the lead in the United States, but he was a municipal politician before be became an ideologue. ${ }^{24}$

Político canadense, prefeito de Westmount, nos subúrbios de Montreal, poeta e romancista, Lighthall se tornou o primeiro secretário honorário da União das Municipalidades Canadenses, reunida pela primeira vez em Toronto em 1901, quando o prefeito de Toronto, Oliver. A. Howland, foi escolhido presidente. As atividades desse importante sindicato podem ser consideradas a coroação da luta pela qual Lighthall vinha se batendo há anos e Biggar observou que: the work of this union made members of parliament a little more careful about handing over to private parties the right to the public resources. ${ }^{25}$

Uma segunda assembleia, ocorrida em junho de 1902 em Berlin, rebatizada posteriormente de Kitchener, reuniu prefeitos que desejavam ambos, os serviços públicos e o fornecimento de energia barata, looking to Niagara as the only source of cheaper power. Nesta ocasião, o vereador Spence declarou que as cidades e vilas queriam energia barata e exortou o Governo Provincial a formar uma comissão que se encarregaria da transmissão de energia elétrica para cidades, vilas e aldeias. Spence era adepto da propriedade pública dos sistemas de distribuição elétrica

Em uma terceira reunião, ocorrida em fevereiro de 1903, ainda em Berlin, cerca de 90 municipalidades e fornecedores individuais estavam representados, incluindo: Toronto, Stratford, London, St. Thomas, Woodstock, Ingersoll, Guelph, Hamilton, St. Catharines, Brantford, Waterloo, Gait, Berlin, St. Mary's, St. Jacobs, Bridgeport. O interesse público no movimento parecia estar sendo definitivamente consolidado.

Quanto a Lighthall, suas acusações contra os monopólios privados incluíam: a perda de receitas municipais; companhias que instalavam postes e fios não apropriados; a recusa das companhias em construir os condutos subterrâneos contratados; obstrução e destruição de ruas; manutenção de tarifas altas e serviços ruins. Em 1901, ele lamentou: we must submit to a future of most shameful imposition to which no other community in any civilized land would submit. ${ }^{26}$

Lighthall ficou muito irritado quando a Montreal Light, Heat and Power Company obteve o monopólio absoluto dos serviços a partir da fusão de várias companhias em Montreal, como já citamos, e que tinha uma população de cerca de 250 mil almas em 1899, alcançando 554.781 em

${ }^{23}$ BEMIS, Edward W. Municipal Monopolies. A Collection of Papers by American Economists and Specialists. 1899. New York: Thomas Y. Crowell \& Company, 1899.

24 ARMSTRONG e NELLES, Monopoly's Moment, p. 142.

25 BIGGAR, Hydro-Electric Development, p. 38.

26 ARMSTRONG e NELLES, Monopoly's Moment, p. 142. 


\section{Khronos, Revista de História da Ciência \\ no 8, dezembro 2019}

1911. Armstrong e Nelles ainda mostram que Lighthall lamentava a condição de torpor moral e político em que as cidades haviam caído e que incentivava for a crusade of redemption. O secretário da União dos Municípios Canadenses conduziu uma campanha contra essa incorporação e, como o conselho da cidade de Montreal não endossou sua luta, chefiou uma delegação que dirigiu uma moção ao governo central, em Quebec. O Premier Simon N. Parent não se comprometeu muito, mas prometeu analisar a matéria e, assim que o prefeito Lighthall desconfiou do posicionamento do Premier, declarou: Parent was crooked.

A argumentação de Lighthall era simples: os serviços públicos só poderiam ser prestados com eficiência pelos monopólios; então a propriedade pública era necessária para evitar os 'males do monopólio'. Assim, podemos dizer que os populistas cívicos tinham soluções simples: controle local ou liberdade municipal, como às vezes era chamado, e propriedade pública das utilities.

Se por um lado, Lighthall era um precursor, Adam Beck, ${ }^{27}$ advogado, fabricante de caixas de charuto e prefeito de London, uma pequena cidade na Província de Ontário, talvez possa ser considerado mais severo em suas proposições. Beck, com paixão e no auge de sua carreira em 1915, defendeu uma província de Ontário sem usinas elétricas de propriedade privada, porque, para ele, os interesses privados não poderiam competir com os interesses dos cidadãos. Devemos reforçar que a regulamentação da propriedade pública da eletricidade em Ontário influenciou o curso da política regulatória em praticamente todo o Canadá depois desses eventos.

Em seu discurso de maio de 1905, já citado, Beck argumentou que acordos feitos com companhias, The Canadian Niagara Power Company, The Ontario Power Company e a The Electrical Development Company, autorizava a exploração de força nas cataratas, mas não protegia o interesse público. Além dos pontos relacionados às perdas dos consumidores, alguns já mencionados, os acordos resultaram em perda de receita para o governo, somente $\$ 60,000$ de receitas pagas naquele tempo, uma quantia considerada insignificante por Beck em vista do potencial das cataratas do Niágara. ${ }^{28}$

A proibição das companhias de se fundirem, evitando a manipulação dos preços pelos açambarcadores, não teria efeito algum no entendimento de Beck, pois nenhuma lei poderia impedir que acionistas de uma das empresas comprasse ações de outras. Assim, o estabelecimento de preços mínimos em condomínios seria um recurso imoralmente utilizado em tais situações e a fusão da Montreal Light, Heat \& Power Company era usada como um exemplo dessa política. A respeito disso, anos depois, foi dito em um relatório da Hydro-Electric Power Commission, que a tendência com companhias privadas era to amalgamate or otherwise destroy competition, and then fix the price according to the slight saving which they may be able to induce particular customers to make.29

${ }^{27}$ Disponível em: http://www.thecanadianencyclopedia.ca/en/article/sir-adam-beck/. Acesso em: 25 set. 2017.

${ }^{28}$ BECK, The Public interest, p. 5.

${ }^{29}$ BIGGAR, Hydro-Electric Development, p. 52. 
Para Beck a questão da fusão era, incidentalmente, complexa, reportando que estava bem desenvolvida nos Estados Unidos, in its highest degree of perfection. ${ }^{30}$ Para ele, era justo que os preços americanos trouxessem um lucro satisfatório aos vendedores de energia, mas não no Canadá. Para sua consternação, em 1918 três companhias foram incorporadas sobre as leis de Nova York, The Niagara Falls Power Company, Hydraulic Power Company of Niagara Falls e CliffElectrical Distributing Company. Consolidação efetuada nos termos de um contrato entre as três empresas datado do mesmo ano. A empresa resultante possuía e operava usinas hidrelétricas nos dois lados das cataratas do Niágara, em Nova York e na Província de Ontário. ${ }^{31}$

Beck manteve um argumento estrito, afirmando que, como a capitalização das companhias das cataratas do Niágara era muito alta, os pagamentos de dividendos sobre o capital investido representavam a imposição de uma tarifa mais cara aos consumidores e às companhias públicas. Acusando que, no entendimento do último governo que havia assinado os contratos, o desenvolvimento não seria prejudicado, mesmo que um punhado de pessoas enriquecesse com os tesouros à custa do público em geral, com o que Beck discordava. E concluiu que era necessário: a rational way the kind and degree of protection that should be accorded the commercial and consuming public of the Province in connection with the utilization of these great sources of wealth. ${ }^{32}$

Desde 1903, o Power Works Act foi aprovado dando aos municípios o direito de geração de energia elétrica para fins municipais e, também, de revenda aos que desejassem comprar luz e força. No entanto, a árdua luta contra as grandes empresas monopolizadoras de eletricidade não estava sendo ganha pelos membros do Populismo Cívico até a eleição de James P. Whitney, o líder da oposição que governou a província de Ontário entre 1905 e 1914. Whitney foi um forte oponente do monopólio privado da exploração do potencial gerador das águas e sentenciou durante sua campanha à eleição: ... waterpower of Niagara should be free as air, not only to the monopolist and friend of government as it used to be, but every citizen, under proper conditions, should be free to utilize the powers that the Almighty has given to the Province. ${ }^{33}$

Quando Whitney assumiu seu mandato, encontrou um acordo ainda não oficialmente executado, preparado pelo seu antecessor, cedendo outros $125 \mathrm{mil} \mathrm{hp}(93.212 \mathrm{~kW})$ para a Electrical Development Co., do sindicato Mackenzie. Whitney prontamente repudiou tal acordo. Contudo, o Power Commission Act de 1903 foi considerado impraticável e revogado, sendo seguido por procedimento mais significativo de Whitney, a criação por outra lei, Act, de julho de 1905, da Hydro-Electric Power Commission de Ontário.

Problemas jurídicos impediram a comissão de operar inicialmente, com mais dois Acts sendo preparados, em 1906 e em 1907, este último considerado a verdadeira carta de nascimento da Hydro Power Commission. A comissão seria formada por três comissários, dois membros

${ }^{30}$ BECK, The Public interest, p. 6.

31 ADAMS, Niagara Power, p. 352.

32 BECK, The Public interest, p. 12-3.

33 ARMSTRONG e NELLES, Monopoly's Moment, p. 155. 
permanentes e um membro do Gabinete Provincial, além do presidente que seria nomeado pelo tenente-governador em conselho. A operação é descrita por Biggar

... the Ontario Government too appointed a government commission invested with power to arrange for the transmission of electrical energy to such cities, towns and villages as desired to take power. [...] The municipalities would in effect, buy power from the commission, which would own the main lines and in turn sell power to manufacturers and while supplying power and light for municipal purposes would furnish light to the citizens at an even rate. ${ }^{34}$

No ano seguinte, 1906, Adam Beck tornou-se o presidente Hydro-Electric Power Commission, adotando propostas como a da concorrência entre empresas públicas e privadas, de acordo com o que já vinha defendendo. A Hydro só tinha direito de comprar e distribuir energia até 1914, quando obteve autorização para gerar energia, podendo comprar ou construir usinas hidrelétricas para tal fim. Com essa ferramenta em mãos, Beck tentou usar sua autoridade para expulsar seus rivais do negócio. ${ }^{35}$

Para Biggar, Beck tornou-se o fearless champion of the public ownership of water powers e sua causa influenciou tão fortemente a opinião pública em tão pouco tempo que os dias de dominação dos assuntos municipais por empresas privadas pareciam estar terminados. ${ }^{36} \mathrm{O}$ que não é totalmente verdade, pois alguns capitalistas da indústria hidrelétrica, como William Mackenzie, mantiveram seus monopólios até pelo menos a sua morte em 1923. Agora, como muitos canadenses olhavam ansiosamente para o potencial das cataratas do Niágara como fonte de energia barata, compartilhá-las com um vizinho poderoso, os Estados Unidos, era um assunto delicado.

Desde 1895-96, a primeira usina de geração em larga escala do mundo operava no lado norte-americano, construída pela The Niagara Falls Hydraulic Power and Manufacturing Company. A questão da fronteira estava bem resolvida desde 1814, com o Tratado de Gent e com a demarcação dos comissários em 1819, como lembramos, mas não a questão do uso das águas das cataratas. Assim, devido ao volume dessas águas, o assunto precisaria ser tratado com cautela. Em 1906-7 a questão havia sido colocada pelos governos dos dois países na International Waterways Commission que deveria discutir amigavelmente sobre questões como direitos de navegação e variação nos níveis dos lagos.

Com uma ligeira divergência, os Comissários recomendaram que não mais do que 36 mil pés cúbicos $\left(1.019 \mathrm{~m}^{3}\right)$ por segundo deveriam ser retirados do lado canadense e não mais do que 18.500 pés cúbicos $\left(524 \mathrm{~m}^{3}\right)$ do lado dos Estados Unidos. Acima de tudo, três pontos deveriam ser considerados no International Boundary Waters Treaty, assinado em 1909: usos para fins

\footnotetext{
34 BIGGAR, Hydro-Electric Development, p. 42-3.

35 ARMSTRONG e NELLES, Monopoly's Moment, p. 190; 210.

36 BIGGAR, Hydro-Electric Development, p. 42.
} 
domésticos ou sanitários; navegação, incluindo o serviço de canais; usos para energia e para fins de irrigação.

E finalmente, uma instituição, o Canadian Public Ownership League formado em Toronto em 1907, havia adotado propostas mais radicais. Para eles, todas as utilities que eram monopólios deveriam ser possuídas e controladas pelo povo e operadas em seu proveito, seja pelos municípios, províncias ou pelo Domínio. A propriedade pública era o objetivo último e os monopólios privados não deveriam ser tolerados. Lighthall, que já era considerado bastante inflexível com o monopólio privado, chamava os membros da Liga de extremistas puros. Para eles, o traço de uma cidade melhor seria resultado da cooperação de todas as pessoas de uma comunidade, trabalhando para um bem comum. As palavras de Frank Spence, um dos membros dessa liga, são bastante indicativas desse radicalismo, tendo profetizado em 1907: Ours is the truer Christianity. ${ }^{37}$

\section{Alguns resultados}

De acordo com Armstrong e Nelles, a primeira utility a confrontar a ameaça da propriedade municipal foi a Consumers' Gas Company de Toronto em 1901, mas desde 1887, essa companhia estava sob forte desaprovação, sendo exigido que seu estatuto corporativo fosse revisado. Em campanha para a prefeitura em 1901, Oliver Howland já pressagiava sobre a empresa they are simply an extension of the ordinary municipal sphere of action. ${ }^{38} \mathrm{E}$, precisamente, um dos primeiros obstáculos ao novo prefeito de Toronto foi a legislação provincial que protegia a empresa contra os objetivos de Howland, forçando-o a negociar. O prefeito obteve permissão para comprar a empresa, mas os vereadores rejeitaram o projeto em 1902. A questão atravessou os anos, vários governos municipais, e somente em 1909, após outra tentativa, a cidade começou a comprar suas ações, obtendo participação na empresa.

Esse caso da empresa de gás de Toronto é emblemático justamente devido a seu difícil e longo desfecho, revelando a dura luta entre os adeptos da propriedade pública e os proprietários das companhias, e também por ter sido o primeiro caso. Armstrong e Nelles listaram vários outros casos, que se multiplicaram após a formação do primeiro grupo de pressão, quando a reunião em Kitchener, Ontário, citada acima, ocorreu em 1903. Como temos visto, depois veio a criação da Hydro-Electric Power Commission de Ontário, com Beck como presidente em 1906 e, em 1907, a cidade de Toronto e outros municípios passaram a votar pela construção de seus próprios sistemas de distribuição.

Em alguns casos, a partida estava quase perdida, com em Vancouver onde R. M. Payne, o controller da British Columbia Electric Railway, lutou ameaçadoramente, evitando a regulamentação provincial. Na carta de 1894, uma cláusula de proteção foi inserida e a cidade tentou exclui-la dos acordos em 1900, mas Payne conseguiu a manutenção da cláusula contra o que ele acusou ser uma violação dos direitos corporativos. Então, a British Columbia Electric Railway preservou

37 ARMSTRONG e NELLES, Monopoly's Moment, p. 148.

38 ARMSTRONG e NELLES, Monopoly's Moment, p. 151-2. 
completamente o monopólio privado na província da Colúmbia Britânica até, pelo menos, 1917, o que demonstra como perspectivas diferentes foram estabelecidas no Canadá.

Em outros casos, a propriedade pública dominou, como em Ottawa, onde o município garantiu uma planta de distribuição, na tentativa de entrar em concorrência com as companhias privadas, quando lower prices prevail, based on the cost of production..$^{39}$ Como não temos espaço para mencionar todos os casos aqui, na tabela abaixo apresentamos alguns deles nas cidades mais importantes do país:

\begin{tabular}{|l|l|l|}
\hline \multicolumn{2}{|c|}{ Quadro 3: Tipos de concessão, por municipalidades. } \\
\hline \multirow{2}{*}{ Monopólio privado } & Montreal & $\begin{array}{l}\text { Montreal Light, Heat and Power Company } \\
\text { monopólio desde 1901, resistência à } \\
\text { regulação da Public Utilities Commission. }\end{array}$ \\
\cline { 2 - 4 } & Vancouver & $\begin{array}{l}\text { British Columbia Electric Railway de R.M. } \\
\text { Payne, monopólio do gás e telefone desde } \\
1900 .\end{array}$ \\
\hline $\begin{array}{l}\text { Propriedade pública } \\
\text { eletricidade }\end{array}$ & Ottawa & $\begin{array}{l}\text { Ottawa Electric, carta federal de 1893, } \\
\text { comprada pela Consumer's Electric em 1901. }\end{array}$ \\
\hline \multirow{2}{*}{$\begin{array}{l}\text { Competição pública - privada } \\
\text { em eletricidade e transportes }\end{array}$} & Winnipeg & $\begin{array}{l}\text { Winnipeg Electric Co., de W. Mackenzie, } \\
\text { competição em gás, eletricidade e } \\
\text { transportes contra a Winnipeg Hydro desde } \\
1911 .\end{array}$ \\
\cline { 2 - 4 } & Toronto & $\begin{array}{l}\text { Toronto Street Railway Company e Toronto } \\
\text { Electric Light Co. de W. Mackenzie, } \\
\text { competição contra a Toronto Hydro Electric } \\
\text { System em 1911 e Consumer's Gas Company } \\
\text { desde 1887. }\end{array}$ \\
\hline
\end{tabular}

Fonte: ARMSTRONG e NELLES, Monopoly's Moment.

Assim, podemos observar uma diversidade de situações, incluindo outras províncias que tentaram regular os serviços públicos: Quebec e Nova Escócia, legislação em 1909; New Brunswick em 1910; Ilha do Príncipe Eduardo em 1911; Manitoba, criação de uma Public Utilities Commission em 1912, todos casos retratados por Armstrong e Nelles. Duas províncias tiveram características específicas: a já mencionada Colúmbia Britânica e Saskatchewan, onde a maior parte das concessionárias sempre foi controlada pelos municípios, sendo desnecessário o regulamento da província.

\section{Algumas Conclusões}

A situação que viemos acompanhando mostra que o chamado Populismo Cívico começou cedo no Canadá, débil em fins do século 19, ganhando força no começo do 20, postulando a propriedade pública das companhias de serviços públicos, as utilities. Quase

\footnotetext{
${ }^{39}$ BIGGAR, Hydro-Electric Development, p. 53
} 
concomitantemente à implantação dos avanços da produção de eletricidade em larga escala, lembrando que em 1891 foi estabelecido o marco, com a bem-sucedida transmissão entre Lauffen e Frankfurt, uma distância de 174 km, projeto do engenheiro C. E. L. Brown da Oerlikon Works. Eis a junção entre o laboratório e a fábrica sendo bem-sucedida, superando as dificuldades de levar maiores quantidades de eletricidade a longas distâncias, enfrentadas há dez anos pelo engenheiro eletricista francês, o cenobita Marcel Deprez, que já vinha demonstrando ser possível carregar ao longe a eletricidade, fazendo-a transmitir por fios.

No Canadá, podemos afirmar que não houve ação abrupta para nacionalizar os serviços públicos, apesar do temor que o movimento do Populismo Cívico despertava, mas a coexistência entre diferentes tipos de concessão, como mostra o quadro 3, com ligeira preponderância para a propriedade pública das companhias de serviços públicos, as utilities. O Populismo Cívico enfrentava a força contrária ao benefício da coletividade, bem representada pela figura paradigmática do capitalista cujo objetivo é obter altos lucros com a manutenção do monopólio, como William Mackenzie, por exemplo, um dos magnatas dos serviços públicos no Canadá.

Essa figura poderia ser apenas um desajuste do sistema capitalista, que causaria mais danos do que benefícios, condenando o sistema ao fracasso? Desajuste, pois permite a concentração de muita riqueza em apenas uma pessoa ou um pequeno e privilegiado grupo de pessoas. A organização pública, representando um grande grupo de pessoas, a coletividade, poderia ser o ajuste no sistema, buscando a redistribuição dos benefícios coletados ou incitando as pessoas a fazê-lo. Poderíamos arriscar usar uma metáfora para expressar essa sentença: uma grande mola espiral que pode ser ajustada pelas ações das pessoas ou grupos, ou se ajusta quando é possível e não exatamente cumprindo sempre uma necessidade.

Por isso, é interessante analisar um caso como o ocorrido no Canadá, pois seria possível ver o momento exato em que o sistema está sendo ajustado ou está se ajustando. O momento exato quando a coletividade percebeu o seu tamanho e poder, forçando uma mudança, sendo bastante otimista em nossa análise. No entanto, é Cila de seis goelas, grande em poder, mas imprevisível na ação. Ao dirigi-la, o Populismo Cívico pode ter reordenado essa força extraordinária que produz riqueza, que é o consumo da coletividade dos serviços públicos: gás, telefone, força e luz e transporte de passageiros, ainda que inconsciente para a maioria de seus componentes. Seus enormes lucros são grandes o suficiente para mudar os rumos de uma nação até!

No Brasil, pelo contrário, houve pouco envolvimento da opinião pública nesse assunto no período e o governo se engajava muito timidamente para defender os consumidores. Aqui, nos parece, pode ser exatamente o ponto em que o sistema não está funcionando muito bem. $\mathrm{E}$ isso ocorre justamente porque o monopólio privado mantido por pequenos grupos é a ferramenta que pode ser usada para concentrar a riqueza em suas mãos, absorvendo-a do grupo que gera a riqueza, a quem normalmente chamamos de povo, ou coletividade.

Os monopólios privados de empresas estrangeiras no Brasil foram mantidos por quase oitenta anos, principalmente nos grandes mercados, as capitais, absorvendo ou levando à falência 
as pequenas companhias nacionais. Assim, a grande massa dos consumidores demandava com a sua necessidade, os serviços públicos desenvolvidos a partir das aplicações técnicas, sendo que a riqueza era captada por um pequeno grupo. O movimento era forte, dinâmico e tornou-se mais e mais interessante, inclusive porque esse sistema era capaz de atrair forças ainda maiores, os trustes estrangeiros, que exploravam essa engrenagem, exercendo a extração dos lucros, desalojando ou cooptando as elites nacionais, ou parte delas, no processo.

Em cidades menores, com o menor interesse dos capitais estrangeiros por esses serviços, vemos o desenvolvimento de empresas de capital nacional, geralmente de pequeno porte, pertencentes a empresários das indústrias incipientes, políticos e / ou cafeicultores. Aqui, os lucros são menores também e as grandes forças do capital não se esforçam para dominar a engrenagem; em geral, um grupo local percebe o potencial desses serviços e começa a exercer a extração de lucros em seu benefício, efetivando acumulação local.

É sabido que ambos os países, Brasil e Canadá, são parte desse mesmo sistema denominado capitalismo. Um estudo de caso que pudesse demonstrar esse tipo de engrenagem funcionando, executando seus movimentos, evidenciando quando o benefício é coletado apenas por poucas pessoas, seria interessante e importante. Se precisamos ou podemos mudar o sistema ou não, é outra questão, mas é importante ver claramente como funciona. 